\title{
AUDITORIA DE GESTIÓN CREDITICIA Y LA RENTABILIDAD DE LA COOPERATIVA DE AHORRO Y CRÉDITO MICROFINANZAS PRISMA (2014-2017)
}

\author{
CREDIT MANAGEMENT AUDIT AND THE PROFITABILITY OF THE PRISMA \\ MICROFINANCE SAVINGS AND CREDIT COOPERATIVE (2014-2017)
}

Milena Guillen Sauñe

Universidad Nacional Mayor de San Marcos Lima, Perú

ORCID: https://orcid.org/0000-0001-8999-669X

Correo electrónico: milis_gs@hotmail.com

\section{RESUMEN}

Objetivo: Determinar cómo la auditoria de gestión crediticia incide en la rentabilidad de la Cooperativas de Ahorro y Crédito Microfinanzas Prisma (COOPAC MFP). Método: El tipo de investigación es no experimental, descriptiva y explicativa. Se recolectó información de fuente primaria, obtenida mediante encuestas, entrevistas a los asesores de créditos y cobranzas e información documental y financiera sobre la COOPAC MFP. Se elaboraron encuestas, entrevistas a los asesores de créditos y cobranzas e información documental y financiera sobre la COOPAC MFP. Resultados: Se evidencia que no hay una buena gestión crediticia en el reclutamiento del personal de crédito y cobranza ni en los procesos de evaluación para la otorgación de un crédito, de una supervisión y de un monitoreo de los riesgos y la cartera vencida. Conclusiones: No existen buenas prácticas de auditoria de gestión crediticia por parte de los asesores de créditos y cobranzas, como el conocimiento de la política y productos crediticios para realizar una evaluación, aprobación y recuperación de créditos, debido a que no reciben capacitación constantemente; esto genera un riesgo crediticio que incide de manera negativa en la rentabilidad de la COOPAC MFP.

Palabras clave: Auditoria; gestión; créditos; riesgos y rentabilidad.
[Recibido: 10/11/2019 Aceptado: 05/03/2020 Publicado: 07/05/2020]

\begin{abstract}
Objective: To determine how the credit management auditing has an impact on the profitability of the Prisma Microfinance Savings and Credit Cooperatives (COOPAC MFP). Method: The type of research is non-experimental, descriptive and explanatory. Primary source information was collected; it was obtained through surveys, interviews with credit and collection advisors and documentary and financial information about COOPAC MFP. Surveys, interviews with credit and collection advisors and documentary and financial information about COOPAC MFP were prepared. Results: It is evident that there is no good credit management in the recruitment of credit and collection personnel or in the evaluation processes for the granting of credit, nor supervision and monitoring of the risks and the overdue portfolio. Conclusions: There are no good practices of credit management auditing by credit and collection advisors, such as knowledge of credit policy and products to perform an evaluation, approval and recovery of credits, because they do not receive constant training; this creates a credit risk that has a negative impact on the profitability of the COOPAC MFP.
\end{abstract}

Keywords: Auditing; management; credits; risks and profitability.

(c) Los autores. Este artículo es publicado por la Revista Quipukamayoc, Universidad Nacional Mayor de San Marcos. Este es un artículo de acceso abierto, distribuido bajo los términos de la Licencia Creative Commons Atribución-NoComercial-Compartirlgual 4.0 Internacional.(http://creativecommons.org/licenses/by-nc-sa/4.0/), que permite el uso no comercial, distribución y reproducción en cualquier medio, siempre que la obra original sea debidamente citadas. 


\section{INTRODUCCIÓN}

El sistema financiero peruano está compuesto por instituciones bancarias, financieras, cajas municipales de ahorro y crédito, cajas municipales de crédito popular y cajas rurales de ahorro y crédito que son autorizadas por la Superintendencia de Banca y Seguros y AFP (SBS), institución encargada de la regulación y supervisión del sistema financiero.

Las cooperativas de ahorro y crédito no están reguladas por la SBS, pero sí están supervisadas por la Federación Nacional de Cooperativas de Ahorro y Crédito del Perú (FENACREP). Actualmente, existen 659 cooperativas identificadas por la FENACREP; sin embargo, la mayoría trabaja de manera informal y son utilizadas para el lavado de activos o para estafas piramidales; además captan ahorros con tasas muy altas y colocan créditos con tasas bajas respecto al promedio del sistema financiero, lo que deteriora el mercado financiero.

La FENACREP no puede obligar a las cooperativas informales a que se sometan a supervisión porque existe una debilidad normativa en el control y fiscalización de ellas; por ello, solo 152 cooperativas de ahorro y crédito a nivel nacional son supervisadas por la FENACREP.

Dentro del Reglamento de las Cooperativas de Ahorro y Crédito No Autorizadas a Operar con Recursos del Público se establece la implementación, tanto de la auditoria interna como externa para un mayor control en sus operaciones, procesos operativos y contables (SBS, 1999).

A falta de herramientas para controlar y evaluar gestiones crediticias, se ha generado una incertidumbre en la gerencia por los bajos indicadores de rentabilidad, debido a los créditos vencidos y a la alta morosidad que además ocasiona pérdidas financieras.

Al no implementarse las prácticas de gestión por parte de la gerencia destinada a la detección de problemas y puntos débiles de la cooperativa de ahorro y crédito, no se podrán medir la eficiencia, eficacia y economicidad en los procesos crediticios.

El mayor impacto en la auditoría de gestión crediticia de las cooperativas de ahorro y crédito, se inicia en el área de recursos humanos con la contratación del personal para el área de negocios, que recluta a los asesores de crédito y ayuda en el desarrollo, formación y manejo de las políticas de crédito.

En el proceso de evaluación crediticia los asesores cometen mayores deficiencias en la colocación de créditos, debido a que no cuentan con experiencia, falta de capacitación y manejo de políticas, además no aplican correctamente la evaluación de las 5 " $\mathrm{C}$ " (carácter, capacidad, capital, colateral y condición); por consiguiente, aprueban y desembolsan créditos sin una exhaustiva evaluación y realizan una colocación acelerada tan solo por alcanzar sus metas e incentivos; ocasionando así un riesgo crediticio. De esta manera los créditos crecen en morosidad y generan gastos administrativos en su recuperación, afectando la rentabilidad en los estados financieros de las cooperativas de ahorro y crédito.

En base a las pérdidas que se observan en los estados financieros en años consecutivos, y debido a los inadecuados manejos en los procesos de otorgación de créditos, se ha detectado que las cooperativas de ahorro y crédito se encuentran en proceso de liquidación, lo que demuestra ineficiencia en los procesos crediticios.

Por tanto, para el control y monitoreo de las gestiones crediticias, las cooperativas deben invertir en sociedades de auditorías externas con personal especializado en temas de gestión crediticia. Sin embargo, son pocas las cooperativas que realizan este tipo de auditoria, debido a que es un proceso muy costoso, por la falta de presupuesto, por no haberlo incluido en los planes operativos anuales de trabajo o por desconocimiento del tema.

La gerencia, la plana administrativa y los colaboradores de la cooperativa no reconocen que la auditoría es una aliada para lograr las metas y objetivos. Por ello los auditores son vistos como los buscadores de errores y no como quienes apoyan en el proceso de sus labores y en el crecimiento de la organización.

Maldonado (2001) afirma que:

La auditoria de gestión es la evaluación multidisciplinaria, independiente, con enfoque de sistemas, del grado y forma de cumplimiento de los objetivos de una organización, de las relaciones con su entorno, así como de sus operaciones, con el objeto de proponer alternativas para el logro más adecuado de sus fines y/o mejor aprovechamiento de sus recursos. (p. 14)

De la definición del autor se colige que, la auditoría de gestión permite brindar sugerencias útiles y recomendaciones para mejorar las gestiones de la empresa, con el propósito de evaluar el grado de eficiencia, eficacia y economicidad.

Por ello el autor define las tres E:

- Eficacia es el grado en que los programas están consiguiendo los objetivos propuestos.

- Eficiencia consiste en lograr la utilización más productiva de bienes materiales y de recursos humanos y financieros. 
- Economía se refiere a los términos y condiciones conforme a los cuales de adquieren bienes y servicios en cantidad y calidad apropiadas, en el momento oportuno y al menor costo posible. (p. 16)

Blanco (2012), de la misma manera, se refiere a la auditoría de la gestión crediticia como el examen que se efectúa a una entidad por un profesional externo e independiente, con el propósito de evaluar la eficacia de la gestión en la relación con los objetivos generales, su eficiencia como organización y su actuación y posicionamiento desde el punto de vista competitivo, con el propósito de emitir un informe sobre la situación global de la misma y la actuación de la dirección.

Asimismo, Encomendero (2001) sostiene que existen dos tipos de auditorías en las Cooperativas de Ahorro y Crédito:

a. Las auditorías internas forman parte del sistema de Control interno de la Cooperativa, y está encargada de cuidar que los lineamientos de políticas emanados de la gerencia o del órgano competente se estén cumpliendo.

Lleva a cabo tanto el control económico del sistema financiero como el de carácter administrativo de la institución; por la naturaleza de sus funciones tiene acceso a toda la documentación e información de la cooperativa.

Sus funciones principales son:

- Elaborar el Plan Anual de Auditoria y otros exámenes especiales según las expectativas del directorio.

- Revisar y evaluar los planes, programas y presupuestos aprobados por las cooperativas.

- Efectuar el control de las actividades administrativas y operacionales de la institución.

- Comprobar el cumplimiento de las recomendaciones y correcciones de las observaciones formuladas por el consejo de vigilancia sobre la marcha de la cooperativa.

- Efectuar inspecciones necesarias a los diferentes órganos y actividades de la cooperativa, a fin de mantener informada a la gerencia sobre las irregularidades o fallas que se detectan.

b. La auditoría externa es una actividad realizada por personal calificado ajeno a la empresa. Consiste en una investigación, revisión analítica de los libros, comprobantes y otros datos de los estados financieros, la evaluación del sistema de control interno vigente a los procedimientos contables utilizados por la empresa, analizando su correcto funcionamiento.

La misión de la auditoria externa se resume en la determinación de observaciones y a la vez proponer e identificar recomendaciones que contribuyan con el mejoramiento de los sistemas evaluados desde la perspectiva de efectividad, eficiencia y de los aspectos relacionados con el mejoramiento del negocio, reducción de contingencias de índole tributario, optimización de recursos, entre otros.

Las auditorías internas y externas, así como las funciones de supervisión que realiza la FENACREP, que se encuentran a su vez bajo el área de supervisión y control de la Superintendencia de Banca y Seguros, están dentro de un marco regulatorio que rige para los bancos y otras entidades financieras (FENACREP, 2017).

De acuerdo con los planteamientos de los autores antes citados podemos afirmar que las auditorías internas son designadas por el consejo de vigilancia y consejo de administración, y forman parte del equipo de trabajo en las cooperativas; en cambio, las auditorías externas son convocadas anualmente a sociedades de auditoria.

Además, luego que el auditor interno entregue sus informes con observaciones y recomendaciones de la evaluación realizada, con apoyo de la gerencia tiene que realizar el seguimiento y monitoreo de las observaciones encontradas para mejorarlas en la organización y no quedarse solo en el informe.

Se han revisado las siguientes investigaciones relacionadas a la auditoria de gestión crediticia y su incidencia en la rentabilidad.

Ticona (2017) en su investigación plantea que:

Las Cooperativas de Ahorro y Crédito se ven afectados por el problema de la alta tasa de morosidad, que deteriora la calidad de la cartera de créditos, se requiere realizar las provisiones, que reducen los remanentes, afecta la rentabilidad, disminuye el patrimonio, reduce la solvencia financiera; entonces la alta tasa de morosidad puede constituir en una de las razones de su quiebra, y salida del mercado financiero de las Cooperativas de Ahorro y Crédito, creando un precedente negativo en el sistema financiero. (p.5)

Ticona (2017) concluye que los factores internos y externos reflejan las debilidades institucionales en el incremento de la morosidad, como también la deficiencia en evaluación crediticia, la falta de preparación en temas de créditos, la deficiente recuperación y el seguimiento inoportuno. 
Así mismo, Chávez (2009) señala en su tesis que:

La auditoría de gestión tiene como objetivo determinar el grado en que se están logrando los resultados o beneficios previstos por la normativa legal, por la propia entidad, el programa o proyecto, según sea el caso; también trata de establecer si la entidad adquiere, protege y utiliza sus recursos de manera eficiente y económica. (p.24)

De la misma manera llega a concluir que tanto la plana administrativa como los trabajadores deben estar capacitados en temas de control e implementación de medidas correctivas y dar la importancia a la auditoria de gestión en la supervisión, monitoreo y seguimiento de medidas correctivas encaminadas a políticas de crédito que permitan alcanzar metas y objetivos oportunamente.

Por otro lado, Westley y Branch (2000) afirman que:

La morosidad ha sido descrita como la causa más importante del fracaso de las cooperativas de ahorro $y$ crédito, lo que refleja el hecho de que a menudo es la razón principal de descapitalización e insolvencia. Las cooperativas de ahorro y crédito no pueden mantener indices de morosidad razonablemente bajos (menores a 5\%) sienten un impacto inmediato en sus ingresos cuando no se recuperan los préstamos. (p.76)

Por último, Guillén (2001) expresa las causas que repercuten en la morosidad:

Políticas flexibles de Crédito, capacidad de pago insuficiente, inexperiencia del deudor en su microempresa, inapropiado fin del préstamo y endeudamiento excesivo del cliente; causando una problemática en las entidades acreedoras cayendo en la mora y el incremento de las provisiones por prestamos vencidos. (p. 129)

En base a los aportes mencionados, se procede a desarrollar la investigación de auditoria de gestión crediticia y su incidencia en la Cooperativa de Ahorro y Crédito Microfinanzas Prisma (COOPAC MFP), de modo que se establezcan herramientas de gestión, como una aliada en los procesos crediticios que permitan evaluar la eficiencia, eficacia y economía de los créditos; con la finalidad de mitigar riesgos crediticios, que se dan con mayor impacto en el proceso crediticio (promoción, evaluación, desembolso y recuperación de créditos) que llevan a un riesgo crediticio ocasionando los créditos vencidos, lo que ocasiona alta morosidad y una mayor provisión en los créditos, que afecta la rentabilidad de la COOPAC MFP.

\section{MATERIAL Y MÉTODOS}

La investigación fue no experimental-descriptiva porque se basó fundamentalmente en la observación de fenómenos tal y como se dan en su contexto natural para después analizarlos (Hernández, Fernández y Batista, 2014). Para medir la fiabilidad se utilizó el alfa de Cronbach, donde se obtuvo $\alpha=0.850$, según los datos y la interpretación de significancia fue de $\alpha=0.29$, lo que demostró que el instrumento es confiable y muy aceptable.

Asimismo, se recurrió a la revisión de 365 expedientes crediticios gestionados por el área de negocios de la Cooperativa de Ahorro y Crédito Microfinanzas Prisma y se elaboró un cuestionario dirigido a los asesores de crédito y gestores de cobranza. Los datos obtenidos fueron debidamente procesados y validados con la herramienta estadística SPSS Statistics 22.

Además, fue de tipo explicativo. Se realizó una revisión bibliográfica de la Memoria anual del FENACREP; del reglamento y de la política de créditos; de documentos de evaluación; de revistas financieras; de informes panorámicos de cooperativas y de documentos afines.

Así mismo, se consideró una población de 7202 expedientes de crédito vinculados directamente al giro, con una muestra aleatoria simple de 365 expedientes de crédito para verificar si se están otorgando los créditos de acuerdo a la política, control de los riesgos de crédito en el proceso crediticio y control de cartera vencida; también se seleccionó una muestra de 32 colaboradores, 28 del área de negocios y 4 del área de cobranza, a quienes se les aplicó una encuesta.

\section{RESULTADOS}

A continuación, se muestran los resultados de la investigación en base a la verificación de los expedientes, para ello se consideró las variables: evaluación crediticia, riesgo crediticio y cartera vencida.

La primera variable es la evaluación crediticia y el método que se consideró es las 5 "C" de la evaluación del crédito, como se observa en la tabla 1.

En la tabla 1 de las 5 "C" de crédito se tomó en cuenta los criterios: carácter, capacidad, capital, colateral y condiciones para la evaluación del crédito, con sus respectivos indicadores que facilitaron la evaluación crediticia en la revisión del expediente.

Los resultados se muestran en la figura 1.

De los 365 expedientes, el $28 \%$ es evaluado por su capacidad crediticia, que se fundamenta en antigüedad de negocio, nivel de deuda y la relación de ingreso y de la deuda. El 25\% es evaluado por su capital, que se basa en nivel de inventarios, activos del negocio y ahorros. El $22 \%$ es evaluado con el carácter, considerando en el proceso el historial crediticio, 
referencias vecinales y comerciales. El 18\% es evaluado con el indicador colateral, basado en cuentas avales, títulos de propiedad de la casa y terrenos agrícolas; y el 7\%, con las condiciones crediticias, a saber, el giro de negocio, tipo de crédito y destino del crédito.

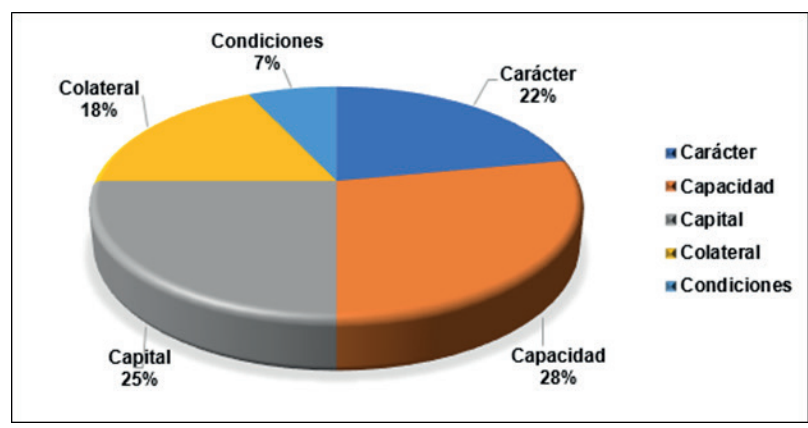

Figura 1. Evaluación crediticia de expedientes según las 5 "C"

Fuente: Elaboración Propia.

Con los resultados obtenidos, se comprobó que el asesor de crédito deberá seguir el flujo crediticio desde la promoción de un crédito hasta la recuperación del crédito. Además deberá utilizar los criterios, como las 5 "C" del crédito y la política de crédito, para seguir con los procesos de aprobación, de desembolso y de recuperación. Para ello, el asesor de crédito deberá seguir los pasos con precisión para que los créditos desembolsados no caigan en morosidad y no dificulten el desarrollo del proceso de otorgación del crédito; así, se reducirá el riesgo crediticio en el proceso crediticio.

La segunda variable es el riesgo de crédito, cuyos resultados se presentan en la figura 2. Se observa que existen 5 créditos con riesgos externos, como actos delictivos generados por el personal de créditos y cobranzas; y 8 con riesgos internos, como enmendaduras en las solicitudes, destino de los créditos que no coinciden con la evaluación y expedientes incompletos.

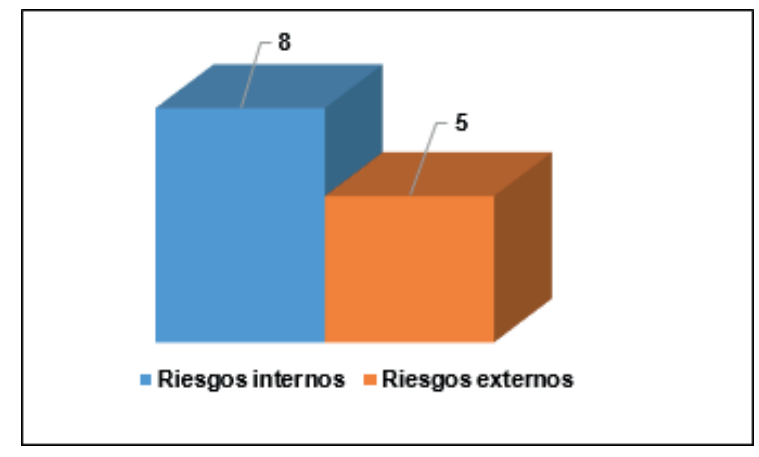

Figura 2. Riesgos internos y externos Fuente: Elaboración propia.

Tabla 1

Evaluación crediticia según las 5 "C" del Crédito

\begin{tabular}{|c|c|c|c|}
\hline & Respuestas & $\begin{array}{c}\text { Cantidad de Expedientes } \\
\text { Revisados }\end{array}$ & $\begin{array}{c}\text { Cantidad de Expedientes en } \\
\text { Porcentaje }\end{array}$ \\
\hline & Historial de Crediticio & & \\
\hline \multirow[t]{3}{*}{ Carácter } & Referencias Vecinales & 81 & $22 \%$ \\
\hline & Referencias Comerciales & & \\
\hline & Antigüedad del Negocio & & \\
\hline \multirow[t]{3}{*}{ Capacidad } & Nivel de Deuda & 101 & $28 \%$ \\
\hline & Relación Ingreso/deuda (30\%) & & \\
\hline & Nivel de Inventarios & & \\
\hline \multirow[t]{3}{*}{ Capital } & Nivel Activos del Negocio & 91 & $25 \%$ \\
\hline & Nivel de Ahorros & & \\
\hline & Cuenta con Avales & & \\
\hline \multirow[t]{3}{*}{ Colateral } & Título de Propiedad de Casa & 66 & $18 \%$ \\
\hline & Título de Propiedad del Terreno Agrícola & & \\
\hline & Giro de Negocio & & \\
\hline \multirow[t]{2}{*}{ Condiciones } & Tipo de Crédito & 26 & $7 \%$ \\
\hline & Destino del Crédito & & \\
\hline TOTAL & & 365 & $100 \%$ \\
\hline
\end{tabular}

Fuente. Elaboración Propia 
La tercera variable es la cartera vencida (figura 3). La cooperativa no gestiona un adecuado seguimiento de créditos como se muestra en la figura, cuyo retraso se encuentra en el rango de 0-8 días, que simboliza el $44 \%$ de la categoría normal.

Los créditos que no tuvieron seguimiento de pago ni fueron gestionados debidamente pasaron a la siguiente categoría con calificación (CPP), que representa el 14\% con un retraso de 9 a 30 días con problemas de potencial. El $11 \%$ tiene un retraso de 31 a 60 días con calificación de deficiente; el $3 \%$ presenta un retraso de 61 a 120 días con calificación de dudoso; y el 3\% tiene un retraso de 121 días a más con una calificación de perdida, pues no han tenido gestión de cobranzas adecuada ni llamadas y visitas a los socios morosos.

Como se observa en los resultados presentados, no existe una óptima gestión crediticia en la cooperativa, por ello, se requiere mayor énfasis en una auditoria de gestión que apoye y ayude a controlar la gestión de la cooperativa en sus diferentes niveles. En este caso, se persigue el objetivo de establecer un control de eficacia, eficiencia y economía (3E), con la finalidad de obtener mayor rentabilidad y solvencia financiera.

\section{DISCUSIÓN}

En base a las encuestas realizadas, se ha demostrado que no existe una buena auditoria de gestión crediticia aplicada por la gerencia, ya que los asesores de créditos no cuentan con los conocimientos necesarios para realizar una evaluación, aprobación y recuperación de créditos.

La razón principal de ello es que la cooperativa no capacita ni entrena continuamente al personal en temas relacionados a créditos y riesgos, incidiendo así en la rentabilidad de la Cooperativa de Ahorro y Crédito Microfinanzas Prisma que afecta económicamente la situación financiera.

Asimismo, como Ticona (2017) refiere, las debilidades institucionales se dan en el reclutamiento del personal, lo cual incide significativamente en el aumento de la morosidad, con mayor relevancia en la deficiencia de la evaluación crediticia elaborada por los asesores de crédito. Las causas son la falta de capacitación constante, la información asimétrica y las múltiples funciones que cumplen los asesores de créditos. Con los problemas presentados, las instituciones tienen que afrontar las altas tasas de morosidad, lo cual afecta negativamente los estados financieros, las provisiones y la solvencia financiera. Esta situación genera disminución del remanente, el patrimonio y la rentabilidad.

Por ello, según Chávez (2009), debe realizarse supervisiones y monitoreos constantes para asegurar el seguimiento de las medidas correctivas adoptadas para el control de riesgos crediticios.

Además, los resultados obtenidos concuerdan con lo propuesto por Parrales (2013), quien sostiene que en el

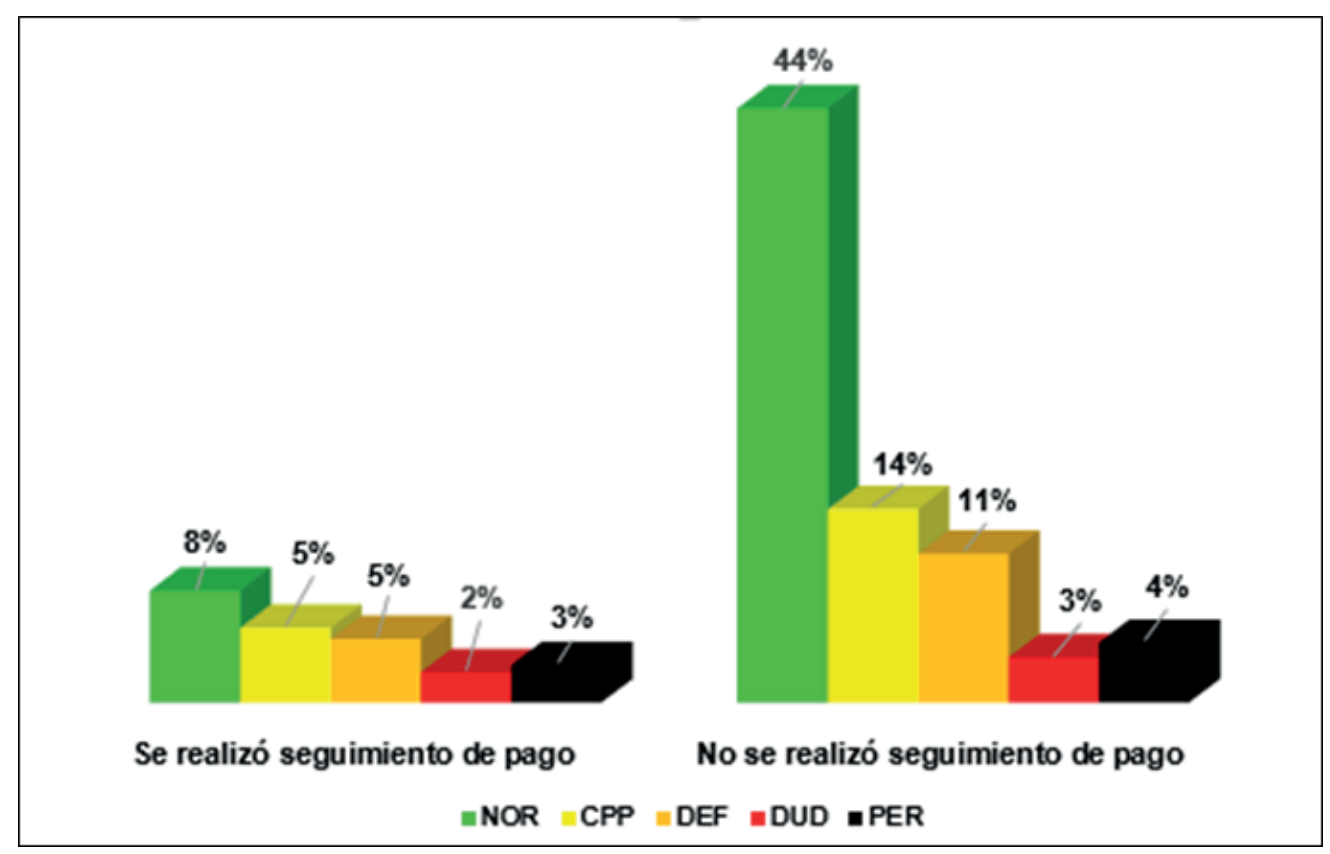

Figura 3. Seguimiento de créditos vencidos Fuente: Elaboración Propia. 
control de la cartera vencida se debe contar con personal suficientemente capacitado para gestionar una efectiva gestión de cobranzas y recuperación.

Finalmente, la investigación concluye que la Cooperativa de Ahorro y Crédito Microfinanzas Prisma debe capacitar continuamente al personal en temas relacionados a créditos y riesgos para que se establezca una buena gestión crediticia que conlleve a realizar mejores evaluaciones crediticias en la otorgación de créditos, control de riesgos y cartera vencida, así favorecer la rentabilidad y solvencia financiera.

\section{REFERENCIAS}

Blanco, L. (2012). Auditoría Integral Normas y Procedimientos (2. ed.). Bogotá: Ecoe Ediciones.

Chávez, E. (2009). La auditoría de gestión en la política del crédito pignoraticio a nivel de cajas municipales de crédito popular (Tesis de maestría). Universidad de San Martín de Porres, Lima. Recuperado de: http://www. repositorioacademico.usmp.edu.pe/handle/usmp/301

Encomendero, A. (2001). Gestión Cooperativa para ser Competitivos. Lima: Editorial OSREVI EIRL.

FENACREP (2017). Memoria Anual 2017. Lima: Federación Nacional de Cooperativas de Ahorro y Crédito del Perú. Recuperado el 20 de febrero del 2018 de:https://www.fenacrep.org/assets/media/documentos/ documentos-nosotros/memorias/memoria-institucional-2017---final_1.pdf

Franklin, E. (2007). Auditoria Administrativa. Gestión estratégica del cambio. México D.F.: Pearson Educación de México.

Guillén, J. (2001). Morosidad crediticia y tamaño: un análisis de la crisis bancaria peruana. Revista Banco Central de Reserva del Perú.
Hernández, R.; Fernández, C. \& Baptista, P. (2014). Metodología de la investigación (6. ${ }^{\mathrm{a}}$ ed.). México D. F.: Editores S.A.

Maldonado, M. (2001). Auditoria de Gestión (2. ${ }^{a}$ ed.). Quito: Editorial Luz de América.

Parrales, C. (2013). Análisis del índice de morosidad en la cartera de créditos de IECE- Guayaquil y propuesta de mecanismos de prevención de morosidad y técnicas eficientes de cobranzas (Tesis de maestría). Universidad Politécnica salesiana, Ecuador. Recuperado de: https://dspace.ups.edu.ec/handle/123456789/5322

Cooperativa de Ahorro y Crédito microfinanzas prisma. (2018). Política de créditos.

Superintendencia de Banca, Seguros y AFP (SBS). (1999). Reglamento de las cooperativas de ahorro y crédito no autorizadas a operar con recursos del público. Recuperado de http: //www2.congreso.gob.pe/sicr/ cendocbib/con4_uibd.nsf/4866416B88806BCC05257B590075E1A1/\$FILE/Resoluci\%C3\%B3n_N\%C2\%B0_0540-1999_Reglamento_Cooperativas.pdf

Ticona, P. (2017). La calidad de la cartera de créditos y su incidencia en la solvencia financiera de las cooperativas de ahorro y crédito de la región puno, 2012-2014 (Tesis de maestría). Universidad Nacional del Altiplano, Puno. Recuperado de: http://repositorio.unap.edu.pe/ handle/UNAP/8110

Westley, D. y Branch, B. (2000). Dinero Seguro. Desarrollo de Cooperativas de Ahorro y Crédito eficaces en América Latina. Washington D.C.: Banco Interamericano de Desarrollo. 
